\title{
Effect of a Training Program Accompanied by a Suggested Diet on Some Physiological Variables and Regulating Blood Sugar Level in Type II Diabetics
}

\author{
Mohammed Nader Shalaby ${ }^{1, *}$, Marwa Ahmed Fadl' ${ }^{2}$, Hoda Abdel Hameed Abdel Wahab ${ }^{2}$, \\ Reda Mohamed Hassan Hashem², Rasha Abd Alfattah Mohammed Faid ${ }^{2}$, Noha Awad Mousa², \\ Mona Fathi Khalil ${ }^{3}$
}

\begin{abstract}
${ }^{1}$ Biological Sciences and Sports Health Department, Faculty of Physical Education, Suez Canal University, Egypt
${ }^{2}$ Department of Self Development, Deanship of Preparatory Year and Supporting Studies, Imam Abdul Rahman Bin Faisal University. Saudi Arabia

${ }^{3}$ Department of Basic Sciences, Deanship of Preparatory Year and Supporting Studies, Imam Abdulrahman Bin Faisal University, Saudi Arabia
\end{abstract}

Received October 5, 2021; Revised January 10, 2022; Accepted February 8, 2022

\section{Cite This Paper in the following Citation Styles}

(a): [1] Mohammed Nader Shalaby, Marwa Ahmed Fadl, Hoda Abdel Hameed Abdel Wahab, Reda Mohamed Hassan Hashem, Rasha Abd Alfattah Mohammed Faid, Noha Awad Mousa, Mona Fathi Khalil, "Effect of a Training Program Accompanied by a Suggested Diet on Some Physiological Variables and Regulating Blood Sugar Level in Type II Diabetics," International Journal of Human Movement and Sports Sciences, Vol. 10, No. 1, pp. 54 - 65, 2022. DOI: 10.13189/saj.2022.100109.

(b): Mohammed Nader Shalaby, Marwa Ahmed Fadl, Hoda Abdel Hameed Abdel Wahab, Reda Mohamed Hassan Hashem, Rasha Abd Alfattah Mohammed Faid, Noha Awad Mousa, Mona Fathi Khalil (2022). Effect of a Training Program Accompanied by a Suggested Diet on Some Physiological Variables and Regulating Blood Sugar Level in Type II Diabetics. International Journal of Human Movement and Sports Sciences, 10(1), 54 - 65. DOI: 10.13189/saj.2022.100109.

Copyright $@ 2022$ by authors, all rights reserved. Authors agree that this article remains permanently open access under the terms of the Creative Commons Attribution License 4.0 International License

\begin{abstract}
Diabetes is one of the most common diseases in our modern era. As a result of the technological evolution recently and the abundance of public and private transportation, in addition to the lack of movement in our societies, many diseases have spread. One of them is diabetes, which is known now as the lack of movement disease. It is one of the most common diseases worldwide. Diabetes comes with a group of diseases called the "lifestyle diseases" like high blood pressure, obesity and heart disease, and other chronic diseases engaged with the technological evolution and lack of movement diseases. The study aimed to identify the effect of the training program accompanied by the proposed diet on some physiological variables and regulating blood sugar levels (diastolic pressure, systolic pressure, cholesterol, triglyceride, high-density cholesterol (HDL), low-density lipoprotein (LDL), fasting blood sugar, non-fasting sugar, cumulative sugar), in type II diabetics. To achieve this, the
\end{abstract}

researchers used the experimental method, as it suited the nature of the study (designed by one experimental group) in a sample of 10 males who were chosen deliberately aged between 45 and 55 years old. The sample members were committed to an eight-week training program accompanied by a diet with three training modules per week. The conclusion of the study showed statistically significant differences between the pre-and post-measurements, in favor of the post-measurement in all variables under study, except for the triglyceride variable. The researchers recommended that sports activity should be practiced regularly in addition to the diet, as it affects regulating blood sugar and controlling its high levels.

Keywords Blood Sugar, Diabetes, Training Program, Diet, Triglyceride, HDL, LDL, Cholesterol 


\section{Introduction}

Diabetes is one of the most common diseases in our modern era. As a result of the technological evolution recently and the abundance of public and private transportation, in addition to the lack of movement in our societies, many diseases have spread. One of them is diabetes, which is known now as the lack of movement disease. It is one of the most common diseases world widely. Diabetes comes with a group of diseases called the "lifestyle diseases" like high blood pressure, obesity and heart disease, and other chronic diseases engaged with the technological evolution and lack movement diseases [1].

W.H.O statistics for 2014 points out that the ratio of diabetes spread is between (2-5\%) of world citizens. (119; www.WHO.int). Mendham et al. [2] and Peterson et al. [3] have pointed out that diabetes arises from an increase in the level of glucose in the blood. It is divided into two types; the first type is called "Insulin-Dependent Diabetes" in which the pancreas produces a small amount of insulin or does not produce it at all. It doesn't respond to medicine except for providing insulin through injection. So, it is called insulin-dependent. The second type is "Non-Insulin Dependent”. It is the most common representing (90-95\%) of patients. In that type, there is no problem in insulin secretion. The problem is that the glucose is not entering the cells because the cell receptors do not respond to insulin or because of a deficiency in these receptors. Insulin is the key that glucose passes into the cells, and this can be treated using sugar-lowering pills. So, it is called Non- Insulin Dependent.

Shalaby et al. [4] and others have agreed that despite the scientific progress of the Americans, this disease has become the most common in the United States due to the high rates of obesity among children and the elderly, and it is believed that 16 million adults and American children have diabetes. And the dangerous thing is that a third of them are ignorant of that. Because this disease can arise gradually over the years with no symptoms, and if it remains without treatment, it can damage every major organ in the body (such as the visual system, the reproductive system).

Shalaby et al. [5] stated that diabetes is one of the common diseases or diseases of the era as some people like to call it. Shalaby et al. [5] indicated that diabetes is a feature of the modern era. As it infects children, youth, and the elderly. And regular physical activity has a clear positive effect on type 2 diabetics. Muscle contractions need the energy to continue, and glucose and fat are the main sources of energy.

Vina et al. [6] stated the clear effect of physical activity on the health and physical aspect of the individual, which works to strengthen the body and develop his physical capabilities so that he becomes able to resist fatigue and reduce the rate of disease infection. Our bodies are designed for movement and every movement that a person makes during his day is a physical effort that differs in its abilities in terms of strength and weakness. And the necessary physiological processes carried out by the body's multiple organs to perform this effort.

Physiological changes occur to the vital body systems and organs affected by physical exertion that was performed once only as a direct response or as a result of the repeated performance of physical exertion and the continuation of performing physical exertion for several weeks as an adaptation process [7]. This is why physical activities have long been the cornerstone of managing type 2 diabetes [8].

Yan et al. [9] added that the practice of physical activity works to form the Mitochondria. Its function is to burn bad fats that cause arteriosclerosis. The number of these mitochondria increased by doing exercise.

Many diabetics neglect self-monitoring of their disease and self-care for themselves through which they can face this disease along with appropriate treatment [10].

Therapeutic feeding is also a component of the treatment plan for the patient and needs to be modified in his daily diet [11].

Several studies and scientific research have dealt with the relationship between diets and sports activities. Therefore adopting an integrated meal has a positive effect on the health of the body. Also, the meal contributes significantly to increasing the immune system's ability to resist various diseases [12].

Lakshminarayanan et al. [12] stressed that a balanced diet is a basis for the treatment of type 2 diabetes, as the food contains balanced components of the number of calories per person.

Church [13] added that eating food properly is the basis of facing diabetes. The best way is to eat food dividedly at different times and the meals to small and distributed through the daytime.

Based on the many clear scientific facts that have been revealed to the researchers that confirm the existence of a correlation between the quality of food and human health and the practice of various sporting activities. As the concern for the quality of the diet and the provision of food elements and groups has a direct positive impact on the health of the individual and society. Also, food has an important role in the process of maintaining the relative balance between the quantities of essential substances in the blood of calcium, magnesium, sugar, iron, etc., where the human body needs constant proportions of organic materials to complete the processes inside the human body. This balance is obtained through eating and absorbing nutrients inside the body through many processes inside the body of the organism. But these facts remain in the fold of neglect if they are not subjected to experiment and scientific research, so the researchers conducted this research to identify the effect of the nutritional sports program on regulating the level of blood sugar of the second type in the research sample on the hope that this research will benefit the individual and society [14].

In conjunction with the development of civilization in 
various areas of life, modern diseases have increased, including diabetes, which is a chronic disease resulting from lack of movement, in addition to the spread of fast-food rich in sugars, fats, and others. It is noticeable that we have in Yemen the spread and increase of type 2 diabetes, due to the consumption of fast foods full of sugars and fats and the lack of physical activity. The problem with type 2 diabetes is what is known as insulin resistance. Insulin cannot open cells in the blood for glucose to enter. These harm diabetics taking medicines, as these drugs help insulin to open cells and glucose to enter them, but if the patient depends on that and does not change his lifestyle, the cell will become saturated with glucose, which leads to the inability of the cell to absorb other amounts of glucose even the inside of it is emptied of glucose. From here comes the problem of the research which is how to identify the effect of the training program accompanying the diet program in regulating the level of sugar in the blood. And it is scientifically proven that the regular practice of moderate physical activity has positive effects on various body functions that have many health benefits for humans [12-14].

Kay [8] indicated that there is an inverse association between exercise and non-insulin-dependent diabetes.

Mendham et al. [2] explained the positive role of athletic activity in the prevention of non-insulin-dependent diabetes through its effect on glucose tolerance.

Peterson et al. [3] also pointed out that athletic activity plays a great role in the patient's life. Along with the right food diet.

Vina et al. [6] agreed with him as he stated that: food diet is the main point in the regulation of diabetes. Whether the patient is treated by a food diet only or in combination with sports athletic activity [2, 3, 6, 8].

For this athletic activity to have a clear effect on some physiological variables about regulating the sugar level in the blood, the patient must have a well-planned training program according to scientific bases derived from recent scientific sources and studies. Considering the functional changes that may occur during training to constantly monitor the patient's health status [14].

\section{Research Aim:}

Identify the effect of a training program accompanied by a proposed diet on some physiological variables and regulate blood sugar levels in type II patients.

\section{Research hypotheses:}

There are statistically significant differences between the pre and post measurements in favor of the post-measurement of the effect of a training program accompanied by a proposed diet in some physiological variables (diastolic pressure, systolic pressure, cholesterol, triglycerides, high-density lipoprotein cholesterol, low-density lipoprotein) and the regulation of blood sugar level in patients the second type.

\section{Research Terms:}

\section{(Blood sugar)}

It is known as blood sugar concentration or blood sugar level, which is the amount of glucose in the blood of a person, as this ratio is an important factor in the homeostatic stability inside the body [15].

\section{Diabetes:}

The American Association defines diabetes as metabolism disturbances characterized by high blood glucose levels that result from high blood glucose levels accompanied by a decrease in the secretion of insulin from the pancreas or the inability of insulin to facilitate the transport of glucose into cells, or both [38].

\section{Second Type Diabetes:}

It means the diabetics who do not depend on insulin in their treatment [16].

\section{The Study Areas:}

Human Area: some diabetics of type II.

Time Area: the program was applied for 2 months between $1 / 8 / 2020$ to $5 / 10 / 2020$.

Place Area: the program was applied in the squares and playgrounds of Ismailia City.

\section{A Previous Study in the Same Topic}

A study was done by Pietro Lucotti et al., Because chronic l-arginine supplementation improves insulin sensitivity and endothelial function in nonobese type 2 diabetic patients, this study aimed to evaluate the effects of a long-term oral l-arginine therapy on adipose fat mass (FM) and muscle free-fat mass (FFM) distribution, daily glucose levels, insulin sensitivity, endothelial function, oxidative stress, and adipokine release in obese type 2 diabetic patients with insulin resistance who were treated with a combined period of hypocaloric diet and exercise training. Thirty-three type 2 diabetic patients participated in a hypocaloric diet plus an exercise training program for 21 days. Furthermore, they were divided into two groups in randomized order: the first group was also treated with l-arginine (8.3 g/day), and the second group was treated with a placebo. Although in the placebo group body weight, waist circumference, daily glucose profiles, fructosamine, insulin, and homeostasis model assessment index significantly decreased, l-arginine supplementation further decreased FM $(\mathrm{P}<0.05)$ and waist circumference ( $\mathrm{P}<0.0001)$, preserving FFM $(\mathrm{P}<0.03)$, and improved mean daily glucose profiles $(\mathrm{P}<0.0001)$ and fructosamine $(\mathrm{P}<0.03)$. Moreover, change in area under the curve of cGMP (second messenger of nitric oxide; $\mathrm{P}<0.001$ ), 
superoxide dismutase (index of antioxidant capacity; $\mathrm{P}<$ $0.01)$, and adiponectin levels $(\mathrm{P}<0.02)$ increased, whereas basal endothelin-1 levels $(\mathrm{P}<0.01)$ and leptin-to-adiponectin ratio $(\mathrm{P}<0.05)$ decreased in the l-arginine group. Long-term oral l-arginine treatment resulted in an additive effect compared with a diet and exercise training program alone on glucose metabolism and insulin sensitivity. Furthermore, it improved endothelial function, oxidative stress, and adipokine release in obese type 2 diabetic patients with insulin resistance [17].

In a study done by Matthew W et al., Adiponectin is an adipocytokine that is hypothesized to be involved in the regulation of insulin action. The purpose of the present investigation was to determine whether plasma adiponectin is altered in conjunction with enhanced insulin action with exercise training. An insulin sensitivity index (SI) and fasting levels of glucose, insulin, and adiponectin were assessed before and after 6 mo of exercise training (4 days/wk for $\sim 45 \mathrm{~min}$ at $65-80 \%$ peak O2 consumption) with no loss of body mass (PRE, $91.9 \pm 3.8 \mathrm{~kg}$ vs. POST, $91.6 \pm 3.9 \mathrm{~kg}$ ) or fat mass (PRE, $26.5 \pm 1.8 \mathrm{~kg}$ vs. POST, $26.7 \pm 2.2 \mathrm{~kg})$. Insulin action significantly $(\mathrm{P}<0.05)$ improved with exercise training (SI +98\%); however, plasma adiponectin concentration did not change (PRE, 6.3 $\pm 1.5 \mu \mathrm{g} / \mathrm{ml}$ vs. POST, $6.6 \pm 1.8 \mu \mathrm{g} / \mathrm{ml})$. In contrast, in a separate group of subjects examined before and after weight loss, there was a substantial increase in adiponectin (+281\%), which was accompanied by enhanced insulin action (SI, $+432 \%)$. These data suggest that adiponectin is not a contributory factor to the exercise-related improvements in insulin sensitivity [18].

In a study done by R. R. Wing et al., Two studies were conducted to determine whether adding exercise to a diet program promotes weight loss or glycaemic control in Type 2 (non-insulin-dependent) diabetic subjects. In Study 1,25 subjects were randomly assigned to diet plus moderate exercise or diet plus placebo exercise. All subjects exercised twice a week as a group and once a week on their own; the diet plus moderate exercise group walked a 3-mile route at each session while the diet plus placebo exercise group did very low-intensity exercises such as stretching and light calisthenics. All subjects followed a calorie-counting diet and were taught behavior modification strategies. Weight losses and improvements in glycaemic control did not differ significantly between the two treatment groups at the end of the 10-week treatment or 1-year follow-up. In Study 2, more extreme conditions were compared: a diet-only group and a diet plus exercise group. The diet plus exercise group walked a 3-mile route with the group 3 times/week and once a week on their own, while the diet-only group was instructed to maintain their current low level of activity. Both groups received comparable diet and behavior modification instruction and therapist contacts. The diet plus exercise group had significantly ( $\mathrm{p}<0.01$ ) better weight losses than the diet only conditions at the end of the 10 -week program $(-9.3 \mathrm{~kg}$ vs $-5.6 \mathrm{~kg})$ and 1-year follow-up $(-7.9 \mathrm{~kg}$ vs -3.8 $\mathrm{kg}$ ). Both groups had similar improvements in glycosylated hemoglobin, but reductions in medication were more frequent and greater in magnitude in the diet plus exercise group. Finally, analyses were conducted collapsing across studies and treatment groups and comparing subjects who reported low, medium, or high levels of exercise at 1 year. The self-reported exercise was related to weight loss and improvements in glycosylated hemoglobin, even after adjusting for weight loss. These data suggest that the combination of diet and exercise improves weight loss and glycaemic control compared to diet only in Type 2 diabetic patients [19].

\section{Research Procedures}

\section{Ethical Statement}

The present study runs in concordance with international ethical standards and applicable local regulatory guidelines. The study does not have any physical, psychological, social, legal, economic, or any other anticipated risks to the study's participants. The study conserves participants' privacy. Investigators are responsible for keeping the security of the data. We also confirm that the participants' data were not used for any other purpose outside this study. Personal data (e.g., name, contact information) were not entered in our data entry software to conserve the participants' privacy, however, each subject got a unique identifier code.

\section{Research Methodology}

The researchers used the experimental method to design the pre-and post-measurements of one experimental group due to its suitability and the nature of the research.

\section{The Research Sample}

The sample members were selected, where they were deliberately chosen, and the sample consisted of 10 male volunteers, whose ages ranged between 45-55 years, were chosen according to the following conditions:

(1) He has type 2 diabetes

(2) Agreeing to join the training and food program and abide by it

(3) He must not be a practitioner of physical and sports activity

(4) Free from heart disease and stress

(5) He must be a non-smoker

Where the homogeneity of the sample was ascertained in the main variables under study, and Table 1 illustrates this. 
Table 1. The arithmetic mean, standard deviation, and skew coefficient of the main research variables

\begin{tabular}{|l|c|c|c|c|c|}
\hline$\#$ & Variables & Measurement units & Mean & SD & Coefficient of torsion \\
\hline 1 & Age & Year & 51.7 & 4.1 & $0.68-$ \\
\hline 2 & Age of disease & Year & 7.8 & 3.1 & 0.51 \\
\hline 3 & Length & $\mathrm{cm}$ & 165.1 & 6.4 & 1.44 \\
\hline 4 & Weight & $\mathrm{kg}$ & 68.2 & 5.8 & 1.41 \\
\hline 5 & Heartbeat at Rest & Beat/min & 75.1 & 5.4 & $0.29-$ \\
\hline 6 & Diastolic pressure & $\mathrm{Mm} \mathrm{Hg}$ & 81.1 & 2.9 & $1.25-$ \\
\hline 7 & Systolic pressure & $\mathrm{Mm} \mathrm{Hg}$ & 143.3 & 5.4 & 0.35 \\
\hline 8 & fasting Blood sugar & $\mathrm{mg} / \mathrm{dL}$ & 185.9 & 55.9 & 0.42 \\
\hline 9 & blood sugar & $\mathrm{mg} / \mathrm{dL}$ & 285.4 & 64.4 & 0.39 \\
\hline
\end{tabular}

Table 1 shows the homogeneity of the sample members in the research variables, where the coefficient of skewness was between $(-3,+3)$.

\section{Tools Used in the Research:}

(1) Electronic scale to measure weight

(2) A tape measure to measure the length

(3) A device for measuring pressure

(4) Electronic stopwatch

(5) A device for measuring the level of sugar in the blood

(6) Medical gauze

(7) Antiseptic or sterilizer for wounds

\section{Exploratory Experiment:}

The researchers applied for the proposed training program (as an exploratory experiment) on the research sample on $23 / 7 / 2020$ to ensure:

A. The suitability of the proposed training program for the research sample.

B. Determining the intensity of training endurance, using the Karvonen equation (maximum pulse rate = 220 - the individual's chronological age).

C. Set the load that is less than the average, which is equivalent to (35\% - 54\%).

D. Adjust the average load, which is equivalent to (55\% $69 \%)$.

E. Set the load that is more expensive than the average, which is equivalent to $(70 \%-80 \%)$.

F. Ensure that those assisting a team of researchers know their duty.

\section{Administrative Procedures:}

The researchers took written undertakings from the members of the research sample before implementing the program to make sure that the sample members were ready to complete the program until its end and their agreement to that.

\section{Application Procedures:}

Pre- measurements:

The researchers made the pre-measurements for the physiological research variables.

\section{The Proposed Training Program:}

The researchers proposed a training program after reviewing many previous studies, research, periodicals, and Arab and foreign references for type II diabetes patients and its relationship to the training and nutritional program after consulting with experts in sports training and nutrition. When proposing the program, the following was considered:

A - The goal of the program B - Program content C Division of time for the program

The program aims to achieve balance or regulation of the level of sugar in the blood and to improve the efficiency of the functional devices for patients with type 2 diabetes. As for the content of the program, it contains three training units (warm-up - main part - closing) at an average of three training units per week and within a time estimated at (30-50) minutes for each training unit and 8 weeks, considering the gradation in training intensity and time so that Training intensity starts from 35\% and try to reach an intensity score of $80 \%$ as a maximum training.

\section{Suggested Food Program:}

The researchers proposed a nutritional program accompanying the proposed training program for type 2 diabetes patients, as they developed a form for the proposed diet program to take expert opinion to express an opinion on the suitability of this program for type II diabetics.

The program contained five meals a day at a rate of 3 main meals and 2 supplementary meals, considering that the meals contain the basic food for the body (carbohydrates, proteins, fats, water) and inappropriate proportions, after consulting therapeutic nutritionists and endocrinologists for patients with type II diabetes and After taking the opinions of the experts, the researchers modified the program and filtered the information that the experts deemed necessary to be present and completed the program in keeping with the revised American Diabetes Association dietary guidelines

The researchers also gave the sample members a paper 
specifying the number of calories in some necessary foods, so that the sample members can know the daily amount that their body needs from food.

The calorie goal was calculated by taking the patient's pre-treatment weight (in $\mathrm{kg}$ ), multiplying by 26, and subtracting 1000calories. Calorie books and self-monitoring diaries were distributed, with the suggested diet program, and subjects were asked to monitor their caloric intake throughout the program attempting to stay below their calorie goal. Subjects were taught to increase their intake of complex carbohydrates, and decrease their intake of fat, in keeping with the revised American Diabetes Association dietary guidelines [38].

Standard behavior was modification strategies for changing their eating habits. These included techniques for slowing down the rate of eating, reducing eating signals in the home environment, dealing with social pressures to eat, pre-planning for special events, and relapse prevention.

\section{Program Application:}

The researchers applied the program for 8 weeks, with 3 training units per week, where the researchers designed a daily and weekly follow-up paper for all members of the research sample throughout the research implementation.

\section{Post-measurements:}

Researchers made dimensional measurements for the research variables.

\section{Research Variables:}

Independent variables:

1- Training program accompanied by a suggested diet program.

Dependent variables:

(1) Diastolic Pressure

(2) Systolic pressure

(3) Cholesterol

(4) Triglyceride

(5) High-density lipoprotein cholesterol
(6) Low-density lipoprotein (LDL) cholesterol

(7) Regulating the level of sugar in the blood (fasting sugar - blood sugar - cumulative sugar)

(8) Statistical Treatments

(9) Researchers used statistical treatments that achieve the research assignment and its goal

(10) The arithmetic mean / standard deviation

(11) Coefficient of torsion

(12) Percentage of improvement according to the following equation: (pre-measurement post-measurement / pre-measurement x 100)

(13) Pearson correlation coefficient

(14) T-test

\section{Presentation and Discussion of Results}

To verify the hypothesis of the research which states that "there are statistical differences between the pre and post measurements and in favor of the post-measurement of the effect of a training program accompanied by a proposed diet on some physiological variables and regulating blood sugar level in type II patients" The researchers used both the arithmetic mean and the deviation Standard, level of improvement, and T-test to identify the significance of the differences between the two measurements of the research sample. Tables 2, 3, 4, and Figures 1, 2, 3 illustrate this.

It is clear from Table 2 and Figure 1 that there are significant differences statistically between the pre and post measurements in favor of the post-measurement in variables: fasting sugar, blood sugar, and cumulative sugar, where the value of " $\mathrm{T}$ " for fasting sugar was 2.83 while the value of " $\mathrm{T}$ " for blood sugar was 6.85 . It also reached the "T" value for cumulative glucose (42.58) which is all less than the level of significance (0.05), meaning that it is a statistical function. The highest percentage of improvement was for the variable "blood sugar" reached (41.72\%), while the lowest rate of improvement was for “Cumulative sugar” reaching (25.89\%).

Table 2. The significance of the differences between the averages of the pre and post measurements of the fasting, breaking, and cumulative sugar variables

\begin{tabular}{|c|c|c|c|c|c|c|c|c|c|}
\hline \multirow{2}{*}{$\#$} & \multirow{2}{*}{ Variables } & \multicolumn{2}{|c|}{ Before } & \multicolumn{2}{|c|}{ After } & \multirow{2}{*}{ \% of improvement } & \multirow{2}{*}{ T Value } & \multirow{2}{*}{ P-Value } & \multirow{2}{*}{ Significant level } \\
\hline & & Mean & SD & Mean & SD & & & & \\
\hline 1 & fasting sugar & 188 & 60.5 & 128.2 & 8.52 & 31.81 & 2.83 & 0.058 & Sig. \\
\hline 2 & blood sugar & 306.1 & 58.1 & 178.4 & 14.95 & 41.72 & 6.85 & 0.001 & Sig. \\
\hline 3 & Cumulative sugar & 11.2 & 1.5 & 8.3 & 1.15 & 25.89 & 42.58 & 0.000 & Sig. \\
\hline
\end{tabular}




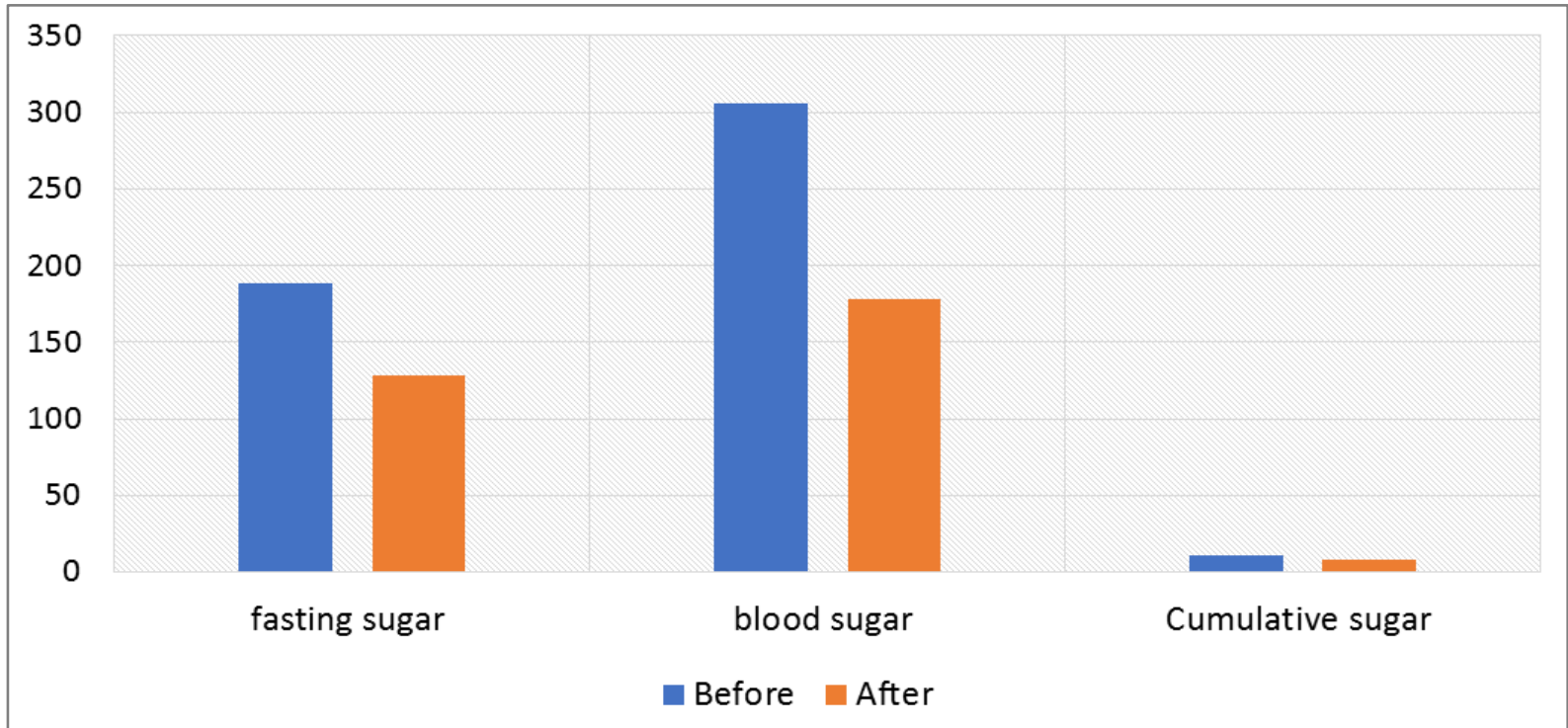

Figure 1. The differences between the averages of the pre and post measurements of the fasting, breaking, and cumulative sugar variables

Table 3. The significance of the differences between the averages of the pre and post measurements of the diastolic, systolic, and triglyceride variables

\begin{tabular}{|c|c|c|c|c|c|c|c|c|c|}
\hline \multirow{2}{*}{$\#$} & \multirow{2}{*}{ Variables } & \multicolumn{2}{|c|}{ Before } & \multicolumn{2}{|c|}{ After } & \multirow{2}{*}{$\%$ of improvement } & \multirow{2}{*}{ T Value } & \multirow{2}{*}{ P-Value } & \multirow{2}{*}{ Significant level } \\
\hline & & Mean & SD & Mean & SD & & & & \\
\hline 1 & Diastolic pressure & 85 & 3.51 & 78 & 5.5 & 8.24 & 7.92 & 0.001 & Sig. \\
\hline 2 & Systolic pressure & 143.1 & 3.31 & 131.1 & 9.3 & 8.39 & 4.52 & 0.008 & Sig. \\
\hline 3 & Triglyceride & 264 & 216.38 & 164 & 102.1 & 37.88 & 2.13 & 0.12 & N. S \\
\hline
\end{tabular}

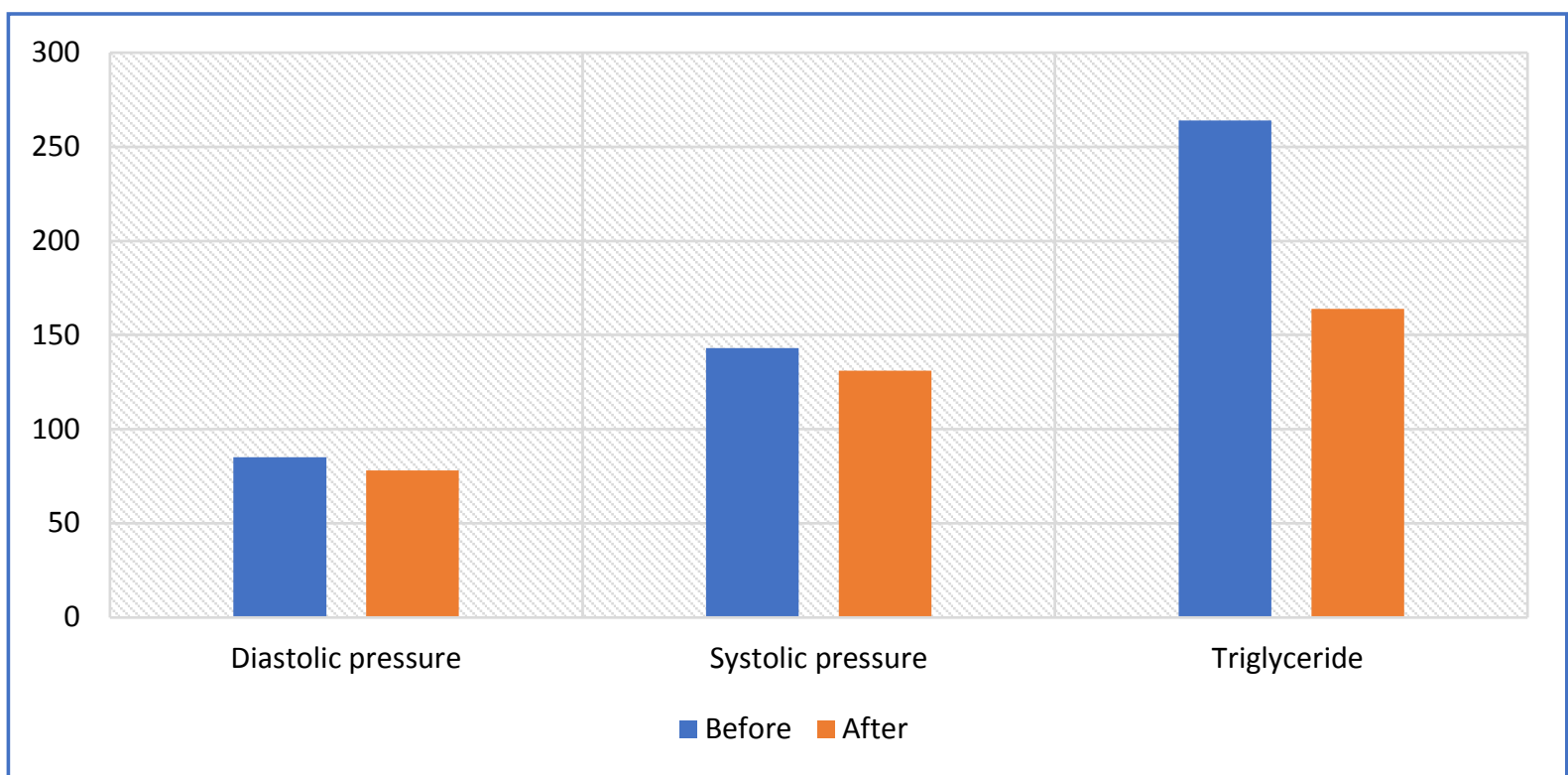

Figure 2. The differences between the averages of the pre and post measurements of the diastolic, systolic, and triglyceride variables

It is clear from Table 3 and Figure 2 that there are statistically significant differences between the pre and post measurements in favor of the post-measurement in the variable of diastolic blood pressure and systolic blood pressure, where the value of $(\mathrm{t})$ was calculated for the diastolic blood pressure (7.92) and systolic (4.52), which is less than the significance level $(0.05)$, while the value of $(\mathrm{t})$ calculated for triglycerides was 2.13, which is greater than the level of significance (0.05), meaning that it is not statistically significant and has reached the highest rate of improvement for a triple variable Glyceride (37.88\%), while the lowest percentage of improvement for the diastolic pressure variable was $8.24 \%$. 
Table 4. The significance of the differences between the averages of the pre-and post-measurements of the variables Cloistral, high-density fats, and low-density fats.

\begin{tabular}{|c|c|c|c|c|c|c|c|c|c|}
\hline \multirow{2}{*}{$\#$} & \multirow{2}{*}{ Variables } & \multicolumn{2}{|c|}{ Before } & \multicolumn{2}{|c|}{ After } & \multirow{2}{*}{$\%$ of improvement } & \multirow{2}{*}{ T Value } & \multirow{2}{*}{ P-Value } & \multirow{2}{*}{ Significant level } \\
\hline & & Mean & SD & Mean & SD & & & & \\
\hline 1 & Cloistral & 193.5 & 40.5 & 175.2 & 31.32 & 9.46 & 3.98 & 0.013 & Sig. \\
\hline 2 & HDL & 35.8 & 8.68 & 40.3 & 6.35 & -12.57 & -4.92 & 0.003 & Sig. \\
\hline 3 & LDL & 126.3 & 29.17 & 112.12 & 24.11 & 11.23 & 4.28 & 0.0076 & Sig. \\
\hline
\end{tabular}

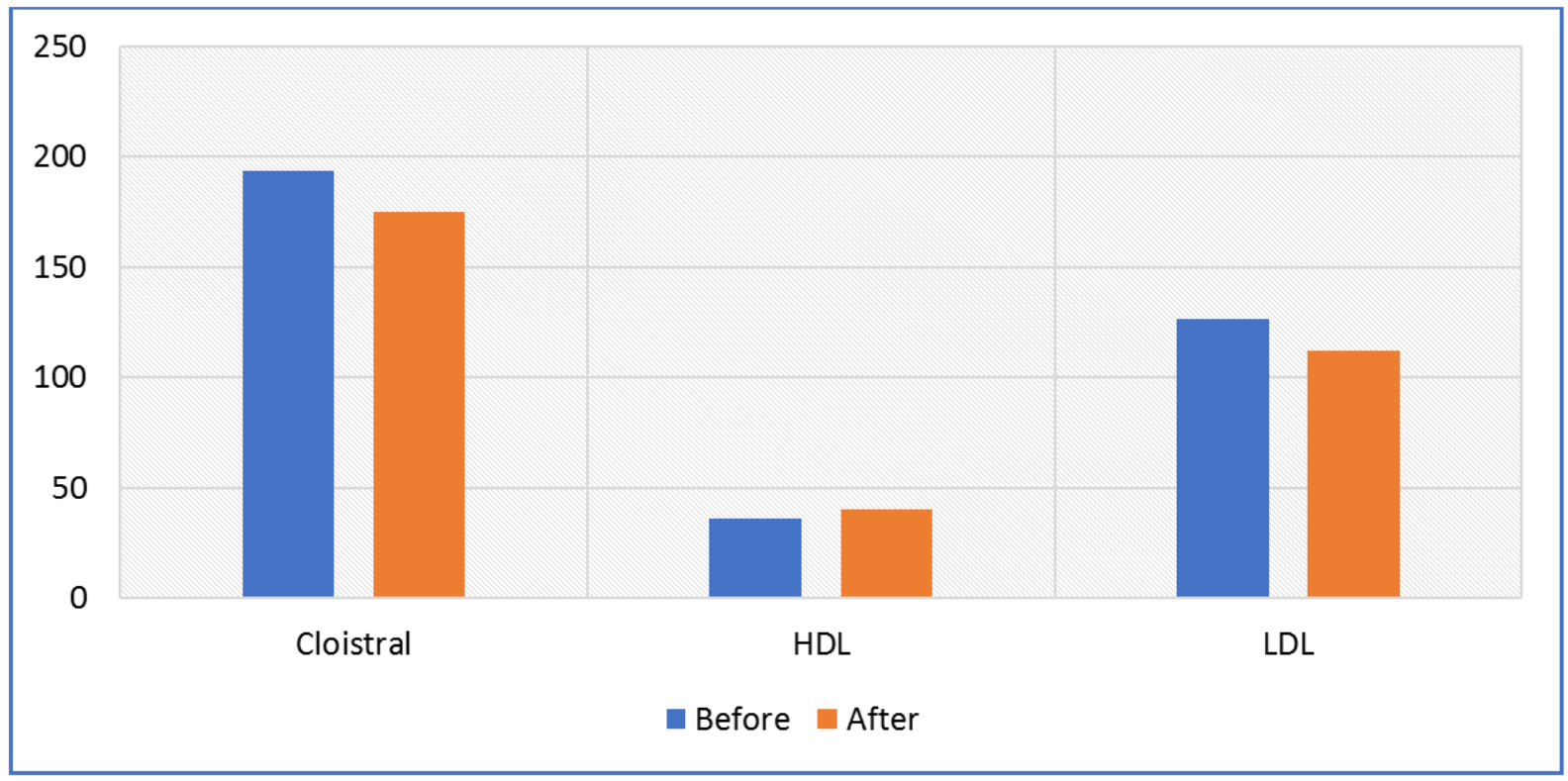

Figure 3. The differences between the averages of the pre-and post-measurements of the variables Cloistral, high-density fats, and low-density fats

It is clear from Table 4 and Figure 3 that there are statistically significant differences between the pre and post measurements in favor of the post-measurement in the variables of cholesterol, high-density fats, and low-density fats, where the calculated value of $(\mathrm{T})$ ranged for cholesterol B (3.98) and fats. High-density B (-4.92) and low-density fats B (4.28), all of which are below the significance level (0.05), meaning that they are statistically significant and have reached the highest improvement rate for the high-density lipid variable $(-12.57 \%)$. While the lowest percentage improvement for the cholesterol variable was 9.46 .

\section{Discussing the Results}

\section{Discussing the results of Table 2 regarding the variables of fasting sugar, blood sugar, and cumulative sugar}

Table 2 shows that there are statistically significant differences between the pre-and post-measurements and in favor of the post-measurement in each of the variables (fasting sugar, blood sugar, cumulative sugar). The researchers attribute these differences to the training program accompanied by the proposed nutritional program in which the graduation was considered. The size and intensity of the training and in line with the chronological age of the sample members and the aerobic exercises such as running and walking in the program, in addition to improving the quality of the individuals' diets by reducing the number of carbohydrates in the suggested diets. When practicing aerobic exercises alongside the proposed diet and drug treatment regularly, the body occurs to have a kind of regulation of blood sugar, and walking and running with dietary regulation helps to control the process of demolition and building in a diabetic. This was confirmed by Kay and Mendham et al. [2, 8] that various exercises, including aerobic, contribute to increasing the sensitivity of cells to the hormone insulin, which increases its effectiveness to perform a function in transporting excess sugar from the blood to muscle and fat cells and thus increasing the metabolism process. For sugar glucose. The improvement resulting from the biological effect of the hormone insulin reduces the peripheral resistance of cells to the effect of the hormone insulin, and this was confirmed by Peterson et al. and Vina et al. [3, 6] in their studies that "the oxidation processes to produce energy in the gums during physical activity increase and multiply to over 50 times, and the consumption of glucose sugar increases to 35 times compared to the time of rest. The results of Table 2 confirm this value, as the blood sugar level decreased 
significantly as a result of applying for this program [2, 3, $6,8]$.

These results are consistent with the studies of Groh et al. and Boily et al. [20, 21] where they showed that aerobic training programs are in addition to the diet. The machine reduces blood sugar levels and helps to burn sugar in tissues, which helps reduce the patient's need for medication. Studies have also shown that the diet has a clear link with diabetes, as avoiding excessive food and adhering to limited food quantities from a nutritionist helps to regulate blood sugar levels, and without it, diabetes cannot be controlled, and its potential complications avoided.

These results also agreed with [7], where the researchers found that aerobic physical activity is graded in intensity and regularity works to reduce the level of glucose in the blood as it works to increase the burning of glucose inside the muscles by increasing the rate of muscle absorption of it from the blood. Thus, its level in the blood decreases as a result of its use in producing the energy required for physical exertion.

In addition to the research agreement with the study of Bacchi et al. [22] and the study and Sieverdes et al. [23] who all confirmed that the aerobic exercise program contributed to an improvement in the blood sugar level of the participants.

\section{Discussion of the results of Table 3 for the variables of diastolic, systolic, and triglyceride blood pressure}

Table 3 shows that there are statistically significant differences between the pre and post measurements in favor of the post-measurement in the variables of diastolic and systolic pressure, and the researchers attribute these differences to the gradation in the intensity and size of the proposed sports exercises in the program, where the chronological age of each of the sample members is considered. As well as increasing the intensity of exercises with improved performance during exercise, in addition to considering the periods of rest between regular exercises. This agrees with the study [24], where he stated that type 2 diabetes patients have resistance to arterial hypotension as a result of physical activities. Shalaby et al. and Leng [25, 26] also emphasized the importance of aerobic physical activity in improving the vital functions of type 2 diabetes are greater than that of anaerobic physical activity [24-26].

These results are also in agreement with the study of Khan et al. [27] that a decrease in the proportion of high fats in the body leads to, in turn, control of blood pressure. It is also evident from Table 3 that there are no statistically significant differences in the triglyceride variable, and the researchers attribute this to the small size of the sample despite the existence of differences between the averages for the pre and post measurements and in favor of the post-measurement, and the improvement rate for triglycerides is one of the largest among the variables. Research in favor of post-measurement, but the small size of the sample led to the failure to reach the required percentage of significance (0.05) although the arithmetic means of the post-measurements of triglycerides reached the normal level [27]

These results are consistent with the results of Collins [28], as they confirmed that the aerobic training program led to an improvement in the health condition and blood sugar level of the patients participating in the program, but that there was no improvement in the level of triglycerides. And Coalter [29] believes that an increase in the percentage of triglycerides in the blood is one of the most important causes of atherosclerosis, as the arteries lose their elasticity and their ability to expand and contract necessary to control blood pressure.

Also, Jarvie [30] confirmed that regular physical exercise reduced the concentration of triglycerides in the blood and that regular physical exercise had positive effects on the composition of the body and the distribution of layers of fat on it.

The study [31, 40] also confirmed that aerobic exercise ridiculously improves the level of triglycerides, in addition to that exercise increases the ridding of the body of triglycerides that harms its health.

These results are also consistent with the results of the study [32, 39] that the aerobic training program has contributed to reducing the complications of the disease by reducing the percentage of triglycerides in the discount, so the exercise of an aerobic training program depends on the production of the energy needed to perform on both fats and carbohydrates. Fats aerobically inside the (beta) cells, which convert it to carbon dioxide, water, and energy that are used in the exercise of activities and thus lead to a decrease in its percentage in the blood [32].

\section{Discuss the results of Table 4 for the variables of cholesterol, high-density fats, and low-density fats:}

Table 4 shows that there are statistically significant differences between the pre-and post-measurements in favor of the pre-measurement in the variables (cholesterol, high-density fats, and low-density fats), where the cholesterol percentage decreased to $10.22 \%$, while the percentage of low-density fats decreased to 11 . The researchers attribute this decrease in the previous two variables to the safety of the nutritional program associated with the training program, as the researchers adopted in their proposed diet program on reducing the number of carbohydrates (sugars and starches) at the expense of increasing both the number of fats and proteins accompanying the regular training program. The more a person regularly exercises, this leads to rapid burning of cholesterol and low-density fats, as the relationship between cholesterol and low-density fats with exercise is an inverse relationship, meaning that whenever a person exercises regularly, this leads to a reduction in cholesterol and low-fat levels Density in the blood.

The study [33] confirmed that the results of the study [34] 
show that there is an inverse relationship between regularity in performing aerobic exercise and the reduction of total cholesterol, as regular exercise leads to an improvement in the percentage of lipids in the blood. Low density will increase the accumulation of cholesterol in the arteries, and the higher the percentage of low-density lipids, the greater the possibility of heart disease, and the greater the percentage of excess cholesterol in the body, which is a source of danger that results in chronic diseases such as type 2 diabetes. A study [29] confirmed that exercise leads to a reduction in the level of low-density lipids and cholesterol in the blood, and the results of this research have been agreed from the study [21]. The training program that applied to the sample members achieved its goals in reducing the proportion of cholesterol and low-density fats [21, 33-35].

Shalaby et al. [33] confirm that the practice of physical activity reduces levels of low-density fats, and the results of this research are consistent with the results of the study of Budiono et al. [36] on a decrease in body fat percentage when exercising regularly, which leads to the prevention of blockage of arteries in the heart. While the percentage of high-density lipids in the blood increased by $-19.71 \%$, where this increase is positive and not negative, as this result is consistent with the study [37] that high-fat percentage is high. Density has a positive effect in reducing cholesterol and low-density lipids in the blood, as the high percentage of high-density fats in the blood and reaching the normal limits (40-60) is an indication of the body's ability to burn cholesterol and harmful fats in the body. It also reduces the incidence of clogged arteries and various heart diseases, in which cholesterol is usually the main responsible for their occurrence. Jarvie [30] also confirmed that regular sporting activity raises the level of high-density lipids in the blood.

It is clear to us that the training program accompanied by the nutritional program has a clear positive effect on some physiological variables and blood sugar of people with type 2 diabetes, and thus the imposition of research is achieved.

\section{Conclusions}

In the light of the researchers' findings, the following was concluded:

- The application of the suggested training program, in general, led to the regulation of blood sugar levels in addition to reducing levels of cholesterol, triglycerides, and low-density fats, and in turn, led to an increase in high-density lipids (beneficial) in addition to regulating the level of systolic and diastolic blood pressure during rest.

- The implementation of the suggested training program accompanied by the proposed diet led to the regulation of blood sugar level (normal - cumulative) and the regulation of blood sugar levels, as well as lowering the levels of cholesterol, triglycerides, and low-density fats (harmful) and in turn lead to an increase in the proportion of high-density fats (beneficial).

- The management program, accompanied by the proposed nutritional program, led to a reduction in the level of some physiological variables in the body under study and better and faster regulation of the sugar level.

\section{Recommendations}

- The need for coordination between the doctor and the sports therapist to control blood sugar levels scientifically and soundly.

- The necessity to exercise regularly, along with food and drug treatments for type II patients.

- The need for a health awareness among all members of society of the importance of exercising regularly and its role in regulating blood sugar levels.

Continuing to conduct experimental research in this field from different angles and variables and by a variety of means.

- The interest of the concerned authorities for the graduates of the Faculty of Physical Education and their involvement in the therapeutic sports market.

\section{Contributions}

The authors of this original article. Collected, organized, and analyzed all of the data utilized in this article and concluded from the results of the data analysis.

\section{Conflict of Interest}

The authors declare no conflicts of interest.

\section{Funding}

The authors declare that there was no outside funding for the writing of this paper.

\section{Ethical Clearance}

Obtained from the departmental committee.

\section{REFERENCES}

[1] Association AD. 5. Prevention or delay of type 2 diabetes: standards of medical care in diabetes-2018. Diabetes Care. 
2018;41(Supplement 1): S51-4.

[2] Mendham AE, Duffield R, Marino F, Coutts AJ. A 12-week sports-based exercise programme for inactive Indigenous Australian men improved clinical risk factors associated with type 2 diabetes mellitus. Journal of Science and Medicine in Sport. 2015;18(4):438-43.

[3] Peterson DD, Kimble JM, Rogers TA, Davis C. A Christian Guide to Body Stewardship, Diet and Exercise. 2020;

[4] Shalaby, M. N., Sakoury, M. M. A., Abdi, E., Elgamal, S., Elrkbwey, S., Ramadan, W., \& Taiar, R. (2021). The Impact of Resistance Training on Gene Expression of IGF1 and Athletes' Physiological Parameters. Open Access Macedonian Journal of Medical Sciences, 9(A), 934-940. https://doi.org/10.3889/oamjms.2021.7215

[5] Shalaby MN, Saad MM. Advanced Material Engineering and Nanotechnology for Improving Sports Performance and Equipment. International Journal of Psychosocial Rehabilitation. 2020;24(10).

[6] Vina J, Tarazona-Santabalbina FJ, Pérez-Ros P, Martínez-Arnau FM, Borras C, Olaso-Gonzalez G, et al. Biology of frailty: modulation of ageing genes and its importance to prevent age-associated loss of function. Molecular aspects of medicine. 2016;50:88-108.

[7] Shalaby MN, Liu JY, Kassem MM, Saad M. Circulating Hematopoietic Stem Cell and Some Physiological Parameters in Different Training Programs. Life Science Journal. 2012;9(1):965-71.

[8] Kay T. Developing through sport: Evidencing sport impacts on young people. Sport in society. 2009;12(9):1177-91.

[9] Yan H, Prista A, Ranadive SM, Damasceno A, Caupers P, Kanaley JA, et al. Effect of aerobic training on glucose control and blood pressure in T2DDM East African males. International Scholarly Research Notices. 2014;2014.

[10] Mohammed Nader Shalaby, Mona Mostafa Sakoury, Marwa Ahmed Kholif, Nagwa Ibrahim Alsayed Albadaly. The role of Amino Acids in improving immunity and growth factors of Volleyball players. J Adv Pharm Edu Res 2020;10(4):140-144.

[11] Cuff DJ, Meneilly GS, Martin A, Ignaszewski A, Tildesley HD, Frohlich JJ. Effective exercise modality to reduce insulin resistance in women with type 2 diabetes. Diabetes care. 2003;26(11):2977-82.

[12] Lakshminarayanan S, Bala SM, Ramanujam M, Kannan G. Effectiveness of physical activity promotion in blood pressure and blood sugar reduction: A community-based intervention study in rural south India. Journal of family \& community medicine. 2012;19(2):81.

[13] Church TS, Blair SN, Cocreham S, Johannsen N, Johnson $\mathrm{W}$, Kramer $\mathrm{K}$, et al. Effects of aerobic and resistance training on hemoglobin A1c levels in patients with type 2 diabetes: a randomized controlled trial. Jama. 2010;304(20):2253-62.

[14] Boule NG, Haddad E, Kenny GP, Wells GA, Sigal RJ. Effects of exercise on glycemic control and body mass in type 2 diabetes mellitus: a meta - analysis of controlled clinical trials. Scandinavian Journal of Medicine \& Science in Sports. 2002;12(1):60-1.
[15] Plowman SA, Smith DL. Exercise physiology for health fitness and performance. Lippincott Williams \& Wilkins; 2013.

[16] Rosenbloom AL, Joe JR, Young RS, Winter WE. Emerging epidemic of type 2 diabetes in youth. Diabetes care. 1999;22(2):345-54.

[17] Lucotti P, Setola E, Monti LD, Galluccio E, Costa S, Sandoli EP, et al. Beneficial effects of a long-term oral l-arginine treatment added to a hypocaloric diet and exercise training program in obese, insulin-resistant type 2 diabetic patients. American Journal of Physiology-Endocrinology and Metabolism [Internet]. 2006 Nov 1;291(5): E906-12. Available from: https://doi.org/10.1152/ajpendo.00002.2006

[18] Hulver MW, Zheng D, Tanner CJ, Houmard JA, Kraus WE, Slentz CA, et al. Adiponectin is not altered with exercise training despite enhanced insulin action. American Journal of Physiology-Endocrinology and Metabolism [Internet]. 2002 Oct 1;283(4):E861-5. Available from: https://doi.org/10.1152/ajpendo.00150.2002

[19] Wing RR, Epstein LH, Paternostro-Bayles M, Kriska A, Nowalk MP, Gooding W. Exercise in a behavioural weight control programme for obese patients with Type 2 (non-insulin-dependent) diabetes. Diabetologia [Internet]. 1988; 31(12): 902-9. Available from: https://doi.org/10.10 07/BF00265375

[20] Groh KJ, Geueke B, Muncke J. Food contact materials and gut health: Implications for toxicity assessment and relevance of high molecular weight migrants. Food and Chemical Toxicology. 2017;109:1-18.

[21] Boily F, Beaudoin S, Measures LN. Hematology and serum chemistry of harp (Phoca groenlandica) and hooded seals (Cystophora cristata) during the breeding season, in the Gulf of St. Lawrence, Canada. Journal of Wildlife Diseases. 2006;42(1):115-32.

[22] Bacchi E, Negri C, Zanolin ME, Milanese C, Faccioli N, Trombetta M, et al. Metabolic effects of aerobic training and resistance training in type 2 diabetic subjects: a randomized controlled trial (the RAED2 study). Diabetes care. 2012;35(4):676-82.

[23] Sieverding M. Panel survey of young people in egypt (sype) 2014. 2014;

[24] Pougnet R, Pougnet L, Lucas D, Uguen M, Henckes A, Dewitte $\mathrm{J}-\mathrm{D}$, et al. Longitudinal change in professional divers' lung function: literature review. International maritime health. 2014;65(4):223-9.

[25] Leng X. Roles of proteasome, arachidonic acid, and oxytocin in bovine myoblast proliferation and differentiation. Virginia Tech; 2018.

[26] Shalaby MN, Fadl MA. Relative Indicators and Predicative Ability of Some Biological Variables on Cardiac Neural Activity for Volleyball Players. Systematic Reviews in Pharmacy. 2020;11(9):834-40.

[27] Khan KM, Thompson AM, Blair SN, Sallis JF, Powell KE, Bull FC, et al. Sport and exercise as contributors to the health of nations. The Lancet. 2012;380(9836):59-64.

[28] Collins M. Sport and social exclusion. Routledge; 2014. 
[29] Coalter F. Sport for development: What game are we playing? Routledge; 2013.

[30] Jarvie G. Sport, culture and society: an introduction. Routledge; 2013.

[31] Shalaby MN, Saad M, Akar S, Reda MAA, Shalgham A. The Role of Aerobic and Anaerobic Training Programs on CD34+ Stem Cells and Chosen Physiological Variables. Journal of Human Kinetics. 2012;35(1):69-79.

[32] Shalaby MN, Sakoury MMA, Hussien S, Mohamed WG, Heikal HF, Rabei MA, et al. The Effect of Using a Suggested Sport's Diet on Increased Thyroid Secretion and Its Effect on Obesity. Systematic Reviews in Pharmacy. 2021;12(1):805-17.

[33] Shalaby, M. N., Sakoury, M. M. A., Hussien, S., \& Abdelghani, M. F. (2022). Studying the Optimal Time for Meals to Circadian Rhythms and Body Health (Application to Hospitality Establishments). Open Access Macedonian Journal of Medical Sciences, 10(A), 108-116. https://doi.org/10.3889/oamjms.2022.8073

[34] Shalaby M, Sakoury MMA, Harthi SM, Alshalawi FM, Alhajji MM, Alshaikh ZH, et al. Vitamin D3 for Health and Muscle Functions of Athletes. Systematic Reviews in Pharmacy. 2020;11(9):851-4.

[35] Coalter F. The politics of sport-for-development: Limited focus programmes and broad gauge problems?
International review for the sociology of sport. 2010;45(3):295-314.

[36] Budiono I, Rahayu T, Kurnia AR. Use of "Nutriatlet” smartphone application-based personalized nutrition program to improve energy consumption, body mass index, and body fat percentage among martial arts athletes. The Journal of Physical Fitness and Sports Medicine. 2019;8(1):29-35.

[37] Coakley J. Youth sports: What counts as "positive development?" Journal of sport and social issues. 2011;35(3):306-24.

[38] American Diabetes Association (1979) Principles of nutrition and dietary recommendations for individuals with diabetes mellitus: 1979. Diabetes 28: 1027-1029

[39] Mohammed Nader Shalaby, Mona Mostafa Abdo Sakoury, Suhailah S. Al-jameel , Ahmad Alghamdi , "The Effect of Diving for Different Years on CD34+ Stem Cells and Some Physiological Variables for Commercial Divers," International Journal of Human Movement and Sports Sciences, Vol. 9, No. 6, pp. 1146 - 1156, 2021. DOI: 10.13189/saj.2021.090610.

[40] M. N. Shalaby and M. A. Fadl, "A Proposed Training Program and Its Effect on Muscle Strength Responses And Some Physiological Variables For Volleyball Beginners," Syst. Rev. Pharm., vol. 11, no. 12, pp. 515-519, 2020. 